\title{
Wer hätte das gedacht?
}

_ Manchmal entwickeln sich die Dinge völlig anders, als man denkt. So auch jüngst das Engagement der Gewerkschaft ver.di, die in Baden-Württemberg bei den Tarifverhandlungen mit den Unikliniken die Abschaffung von Schulgeld für die Physiotherapieausbildung forderte. Dafür holte sie sich die Rückendeckung des Berufsverbands Physio-Deutschland, Landesverband Baden-Württemberg. Überraschenderweise konnte ver.di im Mai ihre Forderung durchsetzen: Das Schulgeld an Unikliniken in Baden-Württemberg ist damit abgeschafft.

_ Ein Grund zur Freude? Für die Physiothera-

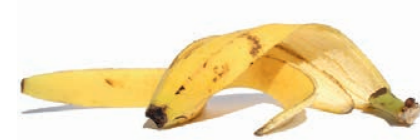
Entpuppt sich die Abschaffung des Schulgeldes an Unikliniken in Baden-Württemberg als Stolperfalle? pieschule an der Uniklinik in Heidelberg ganz und gar nicht. Sie muss nun eine Finanzlücke von 300.000 Euro stopfen (॰ Seite 11). Noch ist unklar, wie. Im Moment sieht es für die Schule mit langer Tradition und bestem Ruf eher schlecht aus. Im Herbst werden keine neuen Schüler eingestellt, und wenn sich keine neue Geldquelle auftut, droht der renommierten Schule möglicherweise das Aus. Damit hatte keiner gerechnet.

_ ver.di und Physio-Deutschland wollen die Abschaffung des Schulgeldes auch auf öffentliche Schulen und Schulen in Mitträgerschaft eines Krankenhauses ausweiten. Auch bei diesen Schulen wird sich die Frage stellen: Wer wird die Finanzlücke schließen? Krankenkassen? Klinische Schulträger? Sozialministerium? Wissenschaftsministerium? ... Sollte die Schulgeldfreiheit flächendeckend kommen und es findet sich keine generelle Lösung, könnte das zu einem Rückgang von Schulen mit klinischen Trägern führen und zu einer Zunahme von privaten Schulen, die wiederum Schulgeld verlangen. Ob dies allerdings im Sinne des Erfinders ist, sei dahingestellt. Wir halten Sie auf dem Laufenden.

Ihre
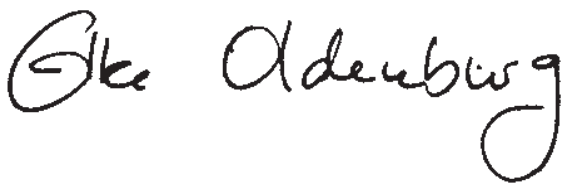